"LA-UR- 97: 662

Title:

\title{
RADIATION FROM HARD OBJECTS
}

Author(s):

Gregory H. Canavan, DDP

Submitted to:

For discussions outside the Laboratory

Date: February 1997
RECEIVED

\section{MAY 051997}

OSTI
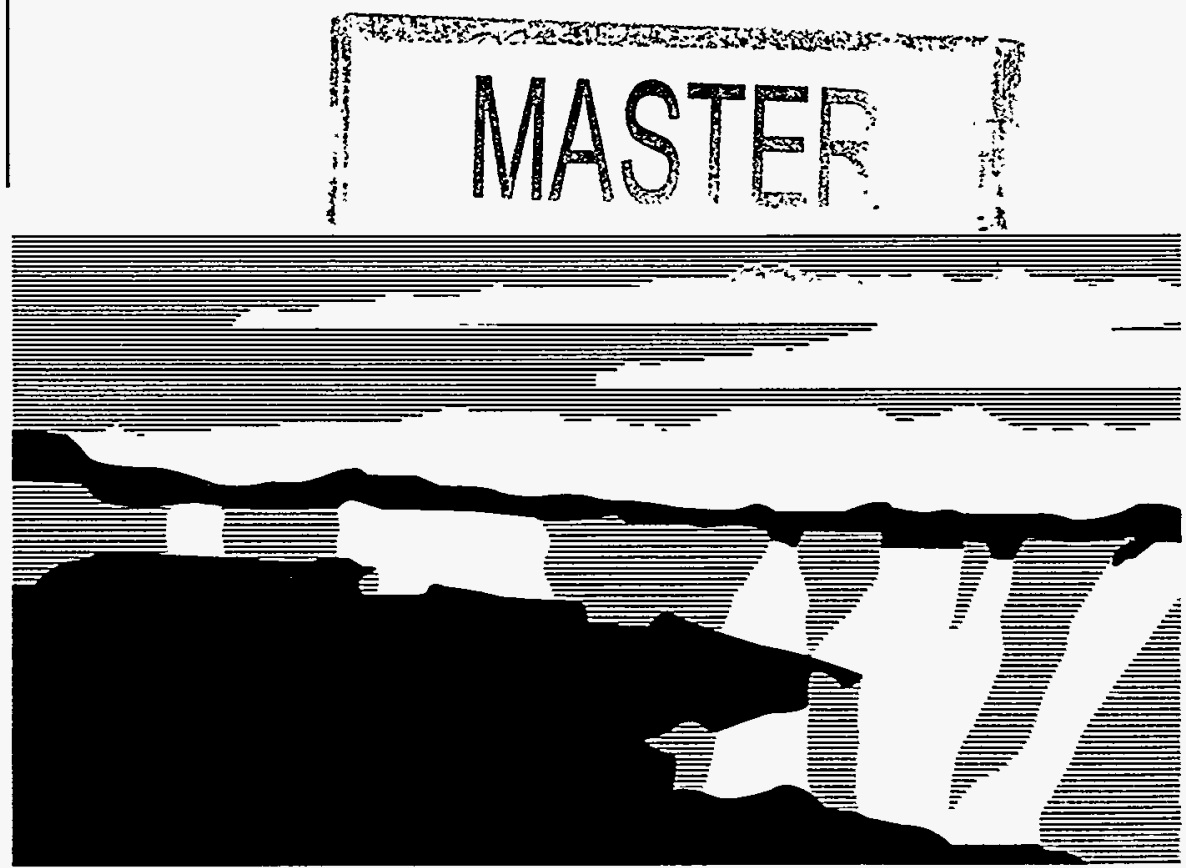

Los Alamos National Laboratory, an atfirmative action/equal opportunity employer, is operated by the University of California for the U.S. Department of Energy under contract W-7405-ENG-36. By acceptance of this article, the publisher recognizes that the U.S. Government retains a nonexclusive, royalty-free license to publish or reproduce the published form of this contribution, or to allow others to do so, for U.S. Government purposes. The Los Alamos National Laboratory requests that the publisher identify this article as work performed under the auspices of the U.S. Department of Energy. 


\section{DISCLAIMER}

This report was prepared as an account of work sponsored by an agency of the United States Government. Neither the United States Government nor any agency thereof, nor any of their employees, make any warranty, express or implied, or assumes any legal liability or responsibility for the accuracy, completeness, or usefulness of any information, apparatus, product, or process disclosed, or represents that its use would not infringe privately owned rights. Reference herein to any specific commercial product, process, or service by trade name, trademark, manufacturer, or otherwise does not necessarily constitute or imply its endorsement, recommendation, or favoring by the United States Government or any agency thereof. The views and opinions of authors expressed herein do not necessarily state or reflect those of the United States Government or any agency thereof. 


\section{DISCLAIMER}

Portions of this document may be illegible in electronic image products. Images are produced from the best available original document. 


\title{
$\angle A-U R-97-662$
}

\section{RADIATION FROM HARD OBJECTS}

\author{
Gregory H. Canavan
}

The inference of the diameter of hard objects is insensitive to radiation efficiency. Deductions of radiation efficiency from observations are very sensitive - possibly overly so. Inferences of the initial velocity and trajectory vary similarly, and hence are comparably sensitive.

This not studies the sensitivity of the radiation signature from hard objects, i.e., ones that do not ablate. It reviews previous work briefly, derives the equations that exhibit the sensitivity of object size and speed to radiation efficiency, and assesses the sensitivity of inferred size and speed to likely variations in efficiency. It indicates the sensitivity of inferred parameters to the radiation efficiency for strong, non-ablating objects. The principal result is that inferences of object diameter are insensitive to radiation efficiency, although deductions of radiation efficiency from observations are very sensitive-possibly overly so. Inferences of the initial velocity vary similarly, and hence are comparably sensitive.

Estimates of radiation efficiency have ranged over two orders of magnitude. These results indicate that a 4-fold uncertainty in observations would be required to produce that range of values. They also indicate that in this approximation the fraction of the kinetic energy radiated by an object is approximately equal to the radiation efficiency, independent of the details of pulse length, altitude, and peak power. Thus, it is necessary to have additional information or to have an accurate estimate of radiation efficiency from without the model. Such an estimate can be produced by more thorough treatments of radiation. This note only provides a framework for assessing the accuracy they must attain to produce useful estimates of object parameters.

Review of earlier work. The kinematics and optical signatures of hard, strong objects entering the atmosphere are simple, because their high heat of vaporization prevents ablation and their great strength prevents break up into smaller pieces. The rate of deceleration of such an abject is given by

$$
\mathrm{MdV} / \mathrm{dt}=-\rho \mathrm{CAV}^{2} \text {, }
$$

where $\rho(z)=$ air density at altitude $\mathrm{z}, \mathrm{A}=$ cross-sectional area, $\mathrm{V}=$ speed, and $\mathrm{C}=$ meteor drag coefficient, which is $\approx 2$ for Newtonian spheres. For hard, strong objects, area does not change, so $\mathrm{A}$ and $\mathrm{M}$ are constant, and it is possible to solve for $\mathrm{V}$ in an exponential atmosphere of scale height $\mathrm{H}$ as

$$
\mathrm{V}=\mathrm{V}_{\mathrm{o}} \mathrm{e}^{-\mathrm{H} \rho} / \beta \sin \theta
$$


where $\beta=M / C A \approx \rho_{a} D$ is the ballistic coefficient of the incident object of density $\rho_{a}$ and diameter $D$ and $\theta$ is its angle of incidence with respect to the horizontal. Equation (2) uniquely relates $\mathrm{V}$ to $\mathrm{z}$ and also determines the radiated power

$$
\mathrm{P}=\mathrm{K}_{\mathrm{CCAV}}{ }^{3}=\mathrm{KCAV}_{\mathrm{O}}{ }^{3} \rho \mathrm{e}^{-3 \mathrm{H} \rho} / \beta \sin \theta \text {, }
$$

where $\mathrm{K}$ is approximately a constant and about a few percent. Thus, the radiated power is also a unique function of $z$. P can be differentiated with respect to $\rho$ to find the density at which the radiated power is a maximum, which is

$$
\text { - } \rho_{\operatorname{maz}}=\beta \sin \theta, / 3 \mathrm{H}
$$

so the peak radiated power is

$$
\mathrm{P}_{\max }=\mathrm{KCAV}_{0}{ }^{3} \rho_{\max } \exp (-3 \mathrm{H} \rho \max / \beta \sin \theta) \text {. }
$$

The altitude of peak radiation is

$$
\mathrm{z}_{\mathrm{maz}}=\mathrm{H} \ln \left(\rho_{\mathrm{o}} 3 \mathrm{H} / \beta \sin \theta\right) \text {. }
$$

The width of the radiation pulse in altitude is $\approx 2 \mathrm{H}$ and in time is $\Delta t=k H / \mathrm{V}_{0}$, where $\mathrm{m} \approx 2$.

Parameter estimates. These result can be inverted to produce an estimates for the object size, speed, and angle of incidence, as discussed in an earlier note. ${ }^{1}$ For the object diameter, that process produces the equation

$$
\mathrm{D} \approx\left[(9 / 2)^{3} \Delta \mathrm{t}^{3} \rho_{\max }{ }^{2} \mathrm{P}_{\max } / \mathrm{K} \rho_{\mathrm{a}}{ }^{3}\right]^{1 / 5},
$$

in terms of the object's radiation pulsewidth $\Delta t$, density of maximum radiation, and maximum power, which can be used to estimate $\mathrm{D}$ from measured quantities. $\mathrm{D}$ depends most strongly on the three measurements $\Delta t, \rho_{\max }$, and $P_{\max }$ and the radiation model parameter $K$. The parametric variation of $D$ with $\Delta t, \rho_{\max }$, and $P_{\max }$ is studied in the earlier note. Of principal interest here is that $D$ depends on the radiation efficiency only through $\mathrm{K}^{1 / 5}$; thus, a precise value of $\mathrm{K}$ is not needed for an accurate estimate of $\mathrm{D}$. Conversely, however, an accurate estimate of $D$ is not necessarily an indication of the accuracy of the value of $K$ used the data interpretation, as $\mathrm{K} \alpha \mathrm{D}^{5}$. Thus, a 32 -fold error in $\mathrm{K}$ would be necessary to make a factor of two error in object diameter, but a 2-fold error in the value of $\mathrm{D}$ could make a

This process also provides equations for the other quantities. The diameter, density, and angle of incidence equations can be inverted to infer the initial object velocity

$$
\mathrm{V}_{0}=\mathrm{m}\left(2 \rho_{\mathrm{a}} \mathrm{D} / 3 \mathrm{C}\right) / 3 \Delta \mathrm{t} \rho_{\max }
$$

which is proportional to $D$. Thus, $V_{0}$ is also weakly sensitive to $K$. The angle of incidence is determined by

$$
\theta=\sin ^{-1}\left(\mathrm{kH} / \mathrm{V}_{0} \Delta \mathrm{t}\right) \text {, }
$$

which scales on $V_{O}$ and hence $K$ as $\sin ^{-1}\left(1 / K^{1 / 5}\right)$. The scaling is strongest for low angles of incidence, i.e., approaches from the horizon; however, the geometry and density approximations used in this model are least accurate there. 
Sensitivity. Figure 1 shows the inferred value of $D$ from Eq. (7) as a function of the altitude at which the radiation is maximum for values of $k$ from 0.01 to 1 for a peak power of $10^{11}$ watts and $\Delta t=0.5 \mathrm{~s}$. The bottom curve is that exhibited for this power in the previous paper. The curves above it represent successive decreases of factors of 3 in $\mathrm{k}$, which produces successive increases of factors of $1 / 3^{1 / 5} \approx 1.25$ increases in $D$ as larger diameters are required to produce the given $P_{\max }$ at lower radiating efficiencies. The fraction of the hard object's energy radiated is roughly equal to $\mathrm{k}$, because from $\mathrm{Eq}$. (5)

$$
\begin{aligned}
\mathrm{P}_{\max } & =\mathrm{KCAV}_{0}{ }^{3} \rho_{\max } / \mathrm{e}=\mathrm{KCAV} \mathrm{O}^{3} \beta \sin \theta, / 3 \mathrm{eH}=\mathrm{KCAV} \mathrm{V}^{2} \beta\left(\mathrm{V}_{\mathrm{o}} \sin \theta, / \mathrm{H}\right) / 3 \mathrm{e} \\
& =\mathrm{KCAV} \mathrm{O}^{2} \rho_{\mathrm{a}} \mathrm{D}(\mathrm{k} / \Delta \mathrm{t}) / 3 \mathrm{e} \approx(4 \mathrm{KCk} / 3 \mathrm{e}) 4 \pi / 3 \rho_{\mathrm{a}}(\mathrm{D} / 2)^{3} \mathrm{~V}_{\mathrm{o}}^{2} / 2 \Delta \mathrm{t} \approx \mathrm{K} \mathrm{E} / \Delta \mathrm{t},
\end{aligned}
$$

where $E$ is the initial kinetic energy of the object. Thus, in this approximation the fraction of the kinetic energy radiated by an object is approximately $K$, independent of the details of $\Delta t, \rho_{\max }$, and $P_{\max }$. The sensitivity of $\theta$ is somewhat less. Estimates of $\mathrm{K}$ have ranged from about $0.3 \%$ to $30 \%$ in the last century. Thus, these results indicate that about a 4-fold uncertainty in D would be required to produce this range of values.

Summary and conclusions. The discussion above indicates the sensitivity of inferred parameters to the radiation efficiency $\mathrm{K}$ for strong, non-ablating objects. The principal result is that inferences of $D$ are insensitive to $K$, although deductions of $K$ from observations of $D$ are very sensitive - possibly overly so. Inferences of the initial velocity vary similarly, and hence are comparably sensitive to $\mathrm{K}$. Estimates of $\mathrm{K}$ have ranged over two orders of magnitude. These results indicate that about a 4-fold uncertainty in observations of $\mathrm{D}$ would be required to produce this range of values. They also indicate that in this approximation the fraction of the kinetic energy radiated by an object is approximately $K$, independent of the details of $\Delta t, \rho_{\max }$, and $P_{\max }$. Thus, it is necessary to have additional information or to have an accurate estimate of $K$ from without the model. Such an estimate can be produced by more thorough treatments of radiation. This note only provides a framework for assessing the accuracy they must attain to produce useful estimates of object parameters.

\section{References}

1. G. Canavan, "Deceleration and Radiation of Strong, Hard Asteroids During Atmospheric Impact," Los Allamos report La-UR-95-1477 rev, 1 February 1977. 


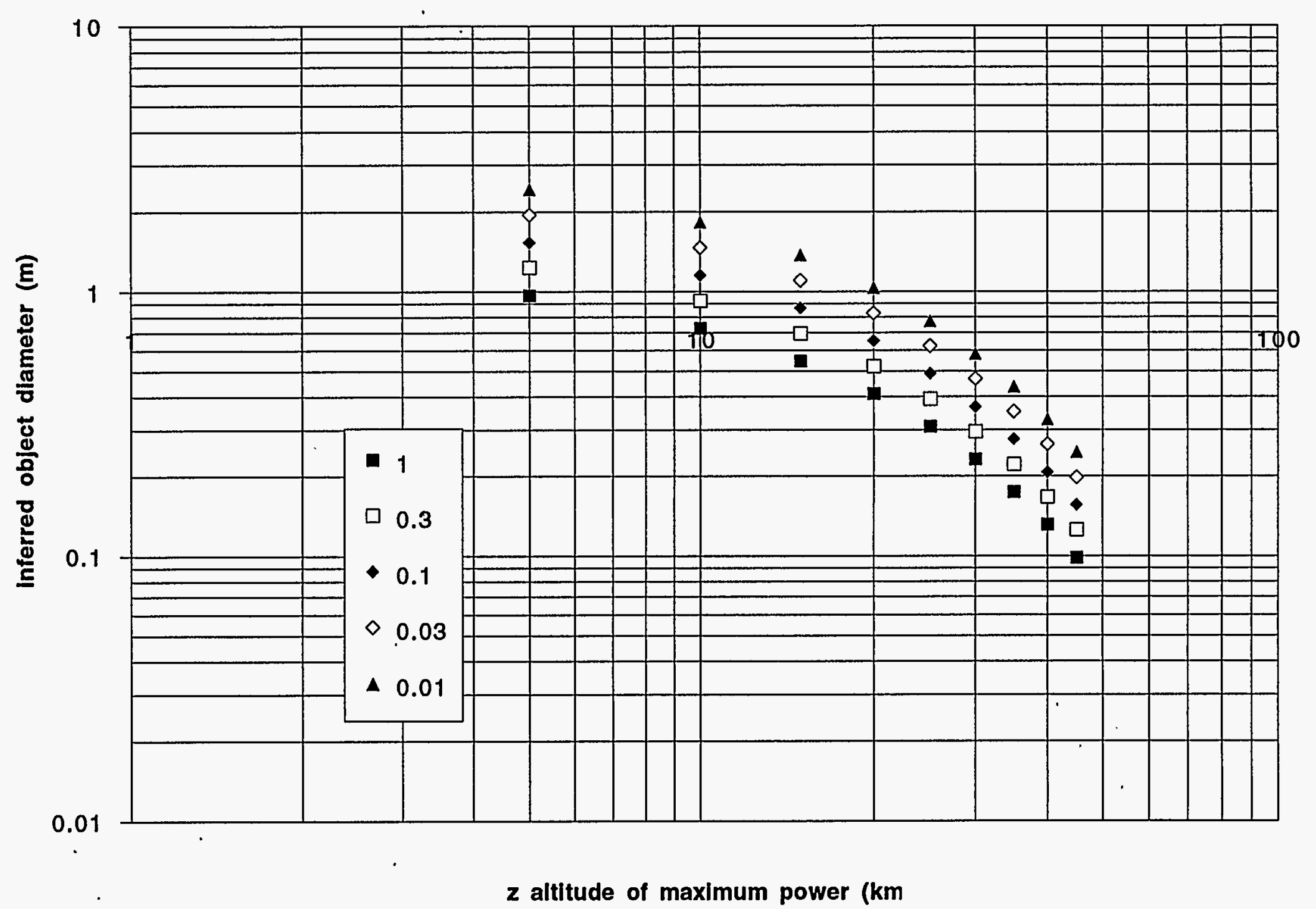

Fig. 1. Inferred object diameter as a function of altitude at which power reaches maximum for various radiation 